\title{
基于改进两步移动搜索法的上海市黄浦区 公园绿地空间可达性分析
}

\author{
任家怿, 王 云* \\ (上海交通大学设计学院,上海 200240)
}

\begin{abstract}
摘 要: 为解决高密度城市公园绿地供需不平衡的问题, 论文提出了一套改进的两步移动搜索模型, 并以上海市黄 浦区为例, 对其现有公园绿地进行步行条件下的空间可达性分析。首先从网络爬取研究范围内居住小区 POI信 息, 将其聚合在边长 $100 \mathrm{~m}$ 的正六边形蜂窝网内, 计算得到每个人口单元的人数及人口密度, 并利用百度地图 API 路径规划接口爬取各供给点和需求点间基于实时路况的出行时间; 其次, 以黄浦区 2019年底已建公园绿地为例, 从居住区人口需求、可达性分级、冷热点和盲区分析 4 个方面对其供需配置进行量化分析, 结果表明, 黄浦区公园 绿地可达性水平整体北高南低, 和人口密度分布呈负相关, 存在供需错位问题, 且仍有 $9.16 \%$ 的显性盲区和 $16.5 \%$ 的隐性盲区亟待消除。研究结果为进一步优化绿地空间布局和选址提供指导依据; 最后从适度增量、盘活存量、社 区共治 3 个方面提出建议, 以期为黄浦区绿化“十四五”规划提供理论支持。
\end{abstract}

关 键 词: 公园绿地可达性; 高斯两步移动搜索法; 细粒度人口; 大数据; 上海市黄浦区

随着中国城市化的不断推进和高密度增长模 式的形成,可用于城市绿化的土地空间资源十分有 限。与此同时, 人们对健康、休闲的需求与日俱增, 对公园绿地提出了更高的功能要求。传统绿地指 标仅强调 “绿地率”或 “人均绿地面积”, 而忽略了对 居民实际需求的分析 ${ }^{[1]}$, 出现了很多虽然总量达标 却局部“供不应求”或“供过于求”的现象。在空间 资源十分有限的情况下, 存量绿地的品质提升以及 增量绿地选址的合理性和公平性成为了重要的 论题。

可达性是由 $\operatorname{Hasen}^{[2]}$ 在 1959 年提出的, 定义为 空间中各节点相互作用的机会大小, 广义的可达性 还包含了空间属性、时间属性和社会经济属性 3 个 维度 ${ }^{[3]}$ 。通常来说, 基于 GIS 技术的可达性计算主 要由度量方法模型、供给和需求量(通常以人口数
量和公共空间面积表示)以及道路空间出行成本(通 常以时间表示)这 3 个方面决定。

可达性常用的度量方法有比例法 ${ }^{[4]}$ 、覆盖法 ${ }^{[5-6]}$ 、 最近距离法 ${ }^{[7]}$ 、引力模型法 ${ }^{[8-9]}$ 和两步移动搜索法 ${ }^{[10-11]}$ 等。其中, 比例法和覆盖法仅从总量或覆盖率上进 行测度, 难以反映服务范围内部的可达性差异; 最 近距离法将居民通行成本作为可达性的度量值, 过 于强调出行阻抗而忽略了公共空间自身等级、质量 等因素; 引力模型虽较为全面地考虑了影响可达性 的多方面因素, 但在许多参数的定义上还存在主观 性, 评价结果不够精确; 两步移动搜索法在引力模 型的基础上加人 “空间阈值” 的概念, 不再拘泥于空 间是否可达,而是从公共空间获得的机会累计值来 衡量其可达性,结果表现形式直观, 且能更好地识 别出可达性的低值区。

收稿日期:2020-06-18; 修订日期: 2020-10-09。

基金项目: 国家社会科学基金重点项目(20BGL215)。[Foundation: Key Program of National Social Science Foundation of China, No. 20BGL215. ]

第一作者简介: 任家怿(1995-), 女, 山西太原人, 硕士生, 主要研究方向为大数据与城市绿地规划。 E-mail: renjiayi1125@163.com

*通信作者简介:王云(1968- ), 男, 江苏南京人,教授,主要研究方向为城市绿地规划与城市景观精细化整治。 E-mail: wangyun03@sjtu.edu.cn

引用格式: 任家怿, 王云. 基于改进两步移动搜索法的上海市黄浦区公园绿地空间可达性分析 [J]. 地理科学进展, 2021, 40(5): 774-783. [Ren Jiayi, Wang Yun. Spatial accessibility of park green space in Huangpu District of Shanghai based on modified two-step floating catchment area method. Progress in Geography, 2021, 40(5): 774-783. ] DOI: 10.18306/dlkxjz.2021.05.005 
在供给量和需求量的数据来源上, 人口分布的 空间数据采集一般有 2 种方式:一是按研究范围内 原有区域划分情况,如街道、社区或居住小区等 ${ }^{[9,12]}$, 单元人口数据仍通过人口普查或统计年鉴获取, 不 仅具有滞后性且无法体现常住人口的真实情况。 此外,行政区域多为不规则形, 搜索时会提取出大 量虽质心已落人、但大部分区域仍在搜索范围外的 需求点, 导致计算结果误差较大 ${ }^{[13]}$ 。针对以上问 题, 尹海伟等 ${ }^{[7]}$ 首次提出利用建筑尺度与单位面积 居住人数来估算人口, 却忽略了建筑层数带来的影 响, 徐彦秒等 ${ }^{[14]}$ 通过卫星影像测算建筑阴影对此进 行改进, 但数据受卫星成像参数影响也会产生较大 误差。第二种方式是将研究区域网格化处理, 以网 格的几何中心作为需求点的重心, 这样虽然降低由 于需求点形状的不规则产生的计算误差, 但已有研 究 ${ }^{[13,15]}$ 均假设人口在网格内均匀分布, 计算结果仍 与真实情况出人较大。

在道路空间数据采集上, 一般通过建立路网模 型来表示地理实体空间, 对于行进途中遇到的十字 路口、天桥、地下通道等阻力所花费时间仅通过估 算获得 ${ }^{[13,16-17]}$, 此类基于经验积累的方法缺乏对实际 路况的把握, 存在较强主观性, 易使计算结果产生 误差, 且对网络进行拓扑分析、矫正检验过程十分 复杂, 人力成本大大增加。

综上, 可达性度量方法的研究还在不断深人, 但在数据的获取和处理上还较依赖于传统方法和 模型估算。在互联网算法快速发展的今天, 结合大 数据的城市绿地空间规划使客观分析与主观经验 相结合, 具有重要的现实意义。鉴于此, 本文探索 性地提出了一种公园绿地的可达性研究框架, 以期 为公园绿地可达性理论的研究与改进提供普适性 的新思路。主要内容为: (1) 利用 Python 爬取互联 网二手房屋交易平台的居住小区 POI(point of interest), 得到小区分布情况和实际户数, 结合每户平均 人数得到小区总人口数; (2) 通过政府网站提取公园 绿地开放数据, 并结合百度地图和外业调研进行篎 选, 借助 ArcGIS 将其转化为空间点; (3) 将研究区域 蜂窝化, 在 ArcGIS 中建立 Polygons 蜂窝网, 将落在 蜂窝网内的居住小区聚合于坐标重心, 得到聚合后 的点位及人口数据; (4) 利用百度地图 API(application programming interface) 中的路径规划接口, 求 得各聚合点到公园绿地的最短出行时间; (5) 在多阈 值搜索下运用高斯两步移动搜索法对公园绿地进
行可达性计算分析。在“上海市 15 min 步行生活 圈”的社区更新政策背景下, 本文选取高密度城区 黄浦区为对象, 应用此研究框架和方法, 对其公园 绿地的步行可达性进行分析。

\section{1 研究区域与数据处理}

\section{1 研究区域}

黄浦区是上海市中心城区之一, 中心坐标为 $121^{\circ} 28^{\prime} 00^{\prime \prime} \mathrm{E} 、 31^{\circ} 13^{\prime} 48^{\prime \prime} \mathrm{N}$, 北起苏州河, 东、南濒黄 浦江, 西至成都北路、延安中路、陕西南路、肇嘉浜 路、瑞金南路, 全区面积为 $20.52 \mathrm{~km}^{2}$ 。截至 2019 年, 黄浦区下辖南京东路、外滩、瑞金二路、淮海中 路、豫园、打浦桥、老西门、小东门、五里桥、半淞园 路 10 个街道(图 1), 共 177 个社区居委会, 常住人口 65.08 万人, 平均人口密度为 3.17 万人 $/ \mathrm{km}^{2}$, 远超过 世界高密度城区 1.5 万人 $/ \mathrm{km}^{2}$ 的指标, 是一个典型 的高密度城区 ${ }^{[18]}$ 。2019 年底黄浦区公园绿地面积 $178.52 \mathrm{hm}^{2}$, 全区绿化覆盖率为 $18.9 \%$, 人均绿地面 积为 $4.4 \mathrm{~m}^{2} /$ 人, 人均公园绿地为 $2.74 \mathrm{~m}^{2} /$ 人。

\section{2 数据来源与预处理}

\subsection{1 步行时间数据}

本文通过百度地图 API 爬取各供给点到需求



图 例
1 南京东路街道
2 外滩街道
3 瑞金二路街道
4 淮海中路街道
5 豫园街道
9 五里桥街道
6 打浦桥街道
7 老西门街道
8 小东门街道
10 半淞园路街道
一 黄浦区道路
•黄浦区行政中心

图 1 黄浦区行政街道分区

Fig.1 Administrative map of Huangpu District, Shanghai 
点的步行时间, 此方法依据实时路况且操作过程简 便。首先利用坐标转换接口, 将供给点和需求点的 GPS 坐标转化为百度坐标; 然后利用路径规划接 口, 以起止点的坐标为参数, 发起步行路径规划请 求, 利用 Python 编程爬取了 10:00、14:00、16:00、 20:00 四个时间点的步行时间数据; 最终通过求平 均值得到每个供给点和需求点间的实际步行时间。

\subsection{2 公园绿地数据}

本文研究的绿地是指公共可进人的、主要供居 民开展日常游憩活动的公园绿地, 包括上海市绿化 市容局网站收录的公园绿地、街头游园、0.04 $\mathrm{hm}^{2}$ 以 上的小微公共绿地和沿江的带状公园。参照 $\mathrm{GBT}$ 51346-2019 城市绿地规划标准》中对公园绿地的 划分标准,将研究区域内的公园绿地划分为 2 大类: I类包含综合公园 (10 $\mathrm{hm}^{2}$ 以上) 和社区公园(1 10 $\left.\mathrm{hm}^{2}\right)$; II 类包含街头游园 $\left(0.2 \sim 1 \mathrm{hm}^{2}\right)$ 和小微公共绿地 $\left(0.04 \sim 0.2 \mathrm{hm}^{2}\right)$ 。

根据《黄浦区单元规划》,提取截至2019年底, 已批控规已建成的所有公园绿地,通过与百度街景 图比对及外业调研篮选, 剔除不可进人、实行收费 以及企事业单位附属绿地, 确定研究区公园绿地共 计 86 处(图 2)。结合黄浦区绿化与市容管理局提供 的绿地面积数据,得到黄浦区公园绿地基本信息如 表1所示。

在 ArcGIS 10.6 平台将公园绿地转换为点要 素。其中, 面状公园绿地可用质心点代表; 黄浦江 带状滨江绿地形状狭长且面积较大, 不宜集中用点 表示, 本文以主干路为分界线, 将原来连续的沿河 绿地分解成段,再分别转化为空间点 ${ }^{[11]}$ 。



图 2 2019年黄浦区公园绿地分布

Fig.2 Distribution of park green space in Huangpu District, Shanghai, 2019

\section{2 .3 人口数据}

人口研究单元的精细程度对可达性结果的准 确性会直接产生影响 ${ }^{[19]}$ 。本文以细粒度的小区人 口聚合点作为研究单元, 从链家网、安居客爬取 2019年底黄浦区小区 POI数据,包含小区名称、地 址、楼栋总数、总户数以及经纬度坐标。已有研究 表明 ${ }^{[20]}$, 正六边形在 6 个方向上的点到质心距离相 同,可减少由于格网形状的边界效应带来的样本偏 差,也更适合进行空间分析(图 3)。因此,本文选择 边长为 $100 \mathrm{~m}$ 的正六边形 ${ }^{[2]}$, 在 ArcGIS 10.6 中建立 Polygons 蜂窝网, 将落在正六边形内的居住小区聚 合于坐标重心, 得到居民点 557 个, 如图 4 所示。各

表 1 黄浦区公园绿地基本信息示例

Tab.1 Examples of some park green space in Huangpu District, Shanghai

\begin{tabular}{|c|c|c|c|c|c|}
\hline 类别 & 面积范围 $/ \mathrm{m}^{2}$ & 公园绿地名称 & 地址 & 所在街道 & 面积 $/ \mathrm{m}^{2}$ \\
\hline \multirow[t]{5}{*}{ I类 } & 100000 以上 & 人民公园 & 南京西路 231 号 & 南京东路街道 & 100000 \\
\hline & & 广场公园(黄浦段) & 金陵西路 50 号 & 南京东路街道 & 159915 \\
\hline & $10000 \sim 100000$ & 古城公园 & 人民路 333 号 & 豫园街道 & 38646 \\
\hline & & 南园公园 & 龙华东路 800 号 & 五里桥街道 & 73350 \\
\hline & & 蓬莱公园 & 南车站路 350 号 & 半淞园路街道 & 35336 \\
\hline \multirow[t]{6}{*}{ II类 } & $2000 \sim 10000$ & 九子公园 & 成都北路 1018 号 & 南京东路街道 & 7000 \\
\hline & & 小桃园绿地 & 复兴东路河南南路 & 老西门街道 & 3700 \\
\hline & & 绍兴公园 & 绍兴路 62 号 & 瑞金二路街道 & 2411 \\
\hline & 400 2000 & 淮茂绿地 & 淮海中路茂名南路 & 瑞金二路街道 & 1189 \\
\hline & & 东门广场 & 金坛路中华路 & 小东门街道 & 500 \\
\hline & & 中山南路苗江路绿地 & 中山南路苗江路 & 半淞园路街道 & 904 \\
\hline
\end{tabular}






(a) 正方形网格



(b) 六边形网格

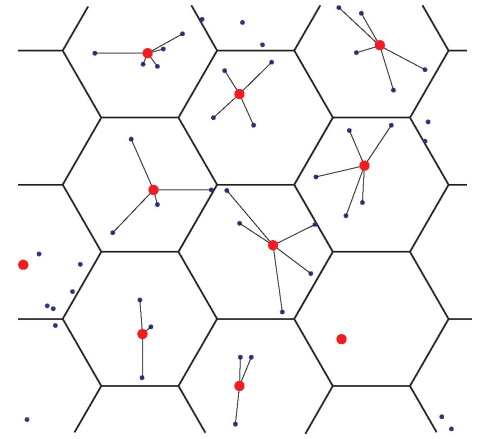

(c) 六边形聚合效果

图 3 基于网格的点聚合效果

Fig.3 Grid-based point aggregation effect

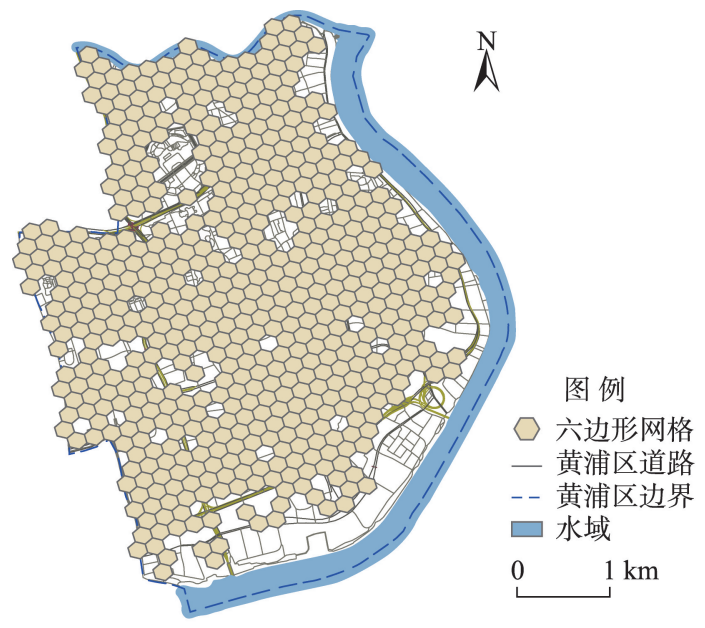

(a) 100 m边长蜂窝网创建

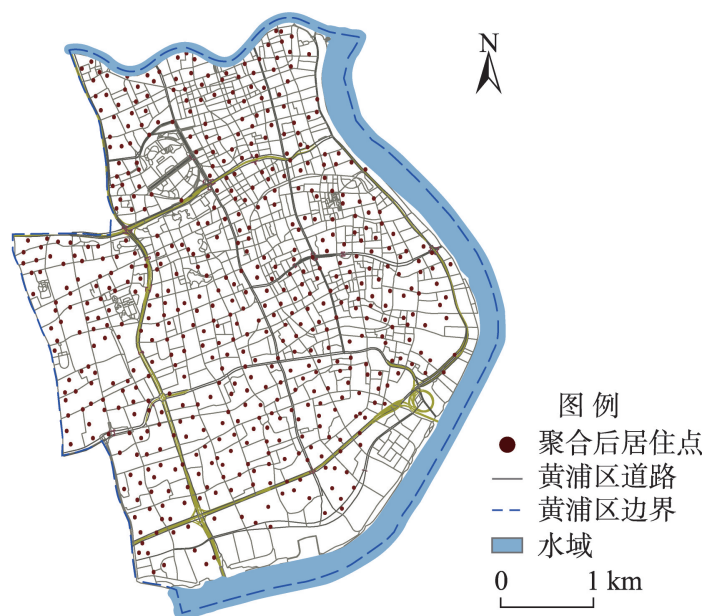

(b) 蜂窝网聚合后的居民点

图 4 2019年黄浦区 100 m边长蜂窝人口数据聚合图

Fig.4 Population data aggregation of $100 \mathrm{~m}$ cellular, Huangpu District, Shanghai, 2019

居民点人口总数用聚合后总户数计算, 公式为:

$$
P_{k}=\sum_{i \in A_{k}} B_{i} \times \bar{M}
$$

式中: $P_{k}$ 为 $k$ 处的人口总数; $A_{k}$ 表示 $k$ 处的六边形; $B_{i}$ 表示位于 $A_{k}$ 内小区的总户数; $\bar{M}$ 为平均每户人口 数, 该数据从《上海年鉴 2019 》中获得, 为 2.4 人/户。 通过《上海年鉴2019》所载的黄浦区各街道常住人 口数据对结果进行校验, 得到聚合人口数据符合真 实人口情况。

\section{2 研究方法}

\section{1 高斯两步移动搜索法}

两步移动搜索法(two-step floating catchment area, 2SFCA) 是由 Radke 等 ${ }^{[10]}$ 于 2000 年提出的, 虽然
克服了过往可达性评价中的众多缺陷,但仍存在以 下不足: 用欧氏距离代替两点之间的实际道路距 离, 且采用 “二分法”判断, 未考虑可达性会随着出 行成本增加呈衰减的趋势 ${ }^{[11]}$ 。因此,Luo 等 ${ }^{[22]}$ 提出一 种增强型两步移动搜索法(E2SFCA), 另有学者将衰 减函数应用于计算, 如核密度函数 ${ }^{[23]}$ 、高斯函数 ${ }^{[24]}$ 、 重力模型 ${ }^{[25]}$ 等; 其次,为所有的供给点设定了相同的 搜索域 $d_{0}$, 而未考虑其规模、品质之间的差异。现有 的改进模型主要有 Luo 等 ${ }^{[26]}$ 的可变半径 $2 \mathrm{SFCA}$ 、

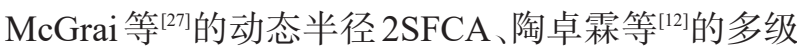
半径 $2 \mathrm{SFCA} 、$ Jamtsho 等 ${ }^{[25]}$ 的最近设施型 $2 \mathrm{SFCA}$ 。 通常来说, 搜索域值主要从两方面确定: 需求者实 际愿意承受的出行距离和相关政策规划 ${ }^{[28]}$ 。

通过对不同函数衰减曲线进行比对, 由于高斯 函数在接近搜索國值时衰减较缓慢, 较符合居民的 
实际出行情况 ${ }^{[29]}$, 本文采用高斯函数 $G\left(d_{k j}, d_{0}\right)$ 来构建 两步移动搜索模型。分为以下 2 个步骤:

第一步, 对于每一个公园绿地供给点 $j$, 搜索所 有以 $j$ 为中心, $d_{0}$ 为阈值范围内的居民需求点 $k$, 对 这些需求点的人口数量用高斯函数进行衰减计算 后求和, 最后用该供给点的面积除以需求点人口之 和得到公园绿地 $j$ 的供需比 $R_{j}$, 即为该公园绿地供 给点的服务能力值:

$$
R_{j}=\frac{S_{j}}{\sum_{k \in\left\{d_{k j} \leqslant d_{0}\right\}} G\left(d_{k j}, d_{0}\right) \times P_{k}}
$$

式中: $S_{j}$ 表示公园绿地 $j$ 的供给规模, 用其面积来衡 量; $d_{k j}$ 表示居民点 $k$ 到公园绿地 $j$ 的步行时间; $P_{k}$ 是 搜索范围内居民点 $k$ 的需求规模, 用人口数量来衡 量; $G\left(d_{k j}, d_{0}\right)$ 是高斯函数,计算公式如下:

$$
G\left(d_{k j}, d_{0}\right)= \begin{cases}\frac{\mathrm{e}^{-\frac{1}{2} \times\left(\frac{d_{k j}}{d_{0}}\right)^{2}}-\mathrm{e}^{-\frac{1}{2}}}{1-\mathrm{e}^{-\frac{1}{2}}} & \left(d_{k j} \leqslant d_{0}\right) \\ 0 & \left(d_{k j}>d_{0}\right)\end{cases}
$$

第二步, 对于每一个居民点 $i$, 搜索所有以 $i$ 为 中心 $d_{0}$ 为阈值范围内的公园绿地 $j$, 同样对每块公 园绿地的供需比 $R_{j}$ 通过高斯函数衰减计算并求和, 最终得到每个居民点 $i$ 的可达性指数 $A_{i}$, 单位是 $\mathrm{m}^{2} /$ 人。

$$
A_{i}=\sum_{i \in\left\{d_{i j} \leqslant d_{0}\right\}} G\left(d_{i j}, d_{0}\right) \times R_{j}
$$

式中: $R_{j}$ 是阈值范围内公园绿地 $j$ 的供需比; $d_{i j}$ 是居 民点 $i$ 与公园绿地 $j$ 之间的步行时间; $A_{i}$ 表示居民点 $i$ 的公园绿地可达性指数,计算得到的 $A_{i}$ 越大, 则表 明位置 $i$ 的可达性越好。

本文是在“上海市 $15 \mathrm{~min}$ 步行生活圈”的政策 背景下展开的, 基于居民的日常游憩需求和行为特 征, 关注步行条件下的公园绿地可达性。在搜索國 值的选择上, 参考《上海市 $15 \mathrm{~min}$ 社区生活圈规划 导则》中各项设施的服务人口和服务半径规定, 将 $\mathrm{I}$ 类公园绿地搜索半径设置为步行 $15 \mathrm{~min}$; II类公园 绿地搜索半径设置为步行 $5 \mathrm{~min}$ 。

\section{2 局域自相关分析}

局域空间自相关性主要衡量研究空间内部局 部区域与相邻空间的关联程度, 利用热点分析 (Getis-Ord $G_{i}^{*}$ ) 来实现 ${ }^{[30]}$ 。 $G_{i}{ }^{*}$ 指标计算结果为 $z$ 得分 (标 准差的倍数)和 $P$ 值(概率), 二者通过逐要素地判断 是否拒绝零假设来进行显著性的统计。如果 $z$ 得分
高且 $P$ 值小, 则为热点地区; 如果 $z$ 得分低、为负数 且 $P$ 值小, 则为冷点地区。 $z$ 得分越高(或越低), 聚 类程度就越大, 如果 $z$ 接近于 0 , 则表示不存在明显 的空间聚类关系。计算公式如下:

$$
\begin{gathered}
G_{i}^{*}=\frac{\sum_{j=1}^{n} w_{i, j} x_{j}-\bar{x} \sum_{j=1}^{n} w_{i, j}}{s \times \sqrt{\frac{n \sum_{j=1}^{n} w_{i, j}^{2}-\left(\sum_{j=1}^{n} w_{i, j}\right)^{2}}{n-1}}} \\
s=\sqrt{\frac{\sum_{j=1}^{n} x_{j}}{n}} \\
s=\sqrt{\frac{\sum_{j=1}^{n} x_{j}^{2}}{n}-\bar{x}^{2}}
\end{gathered}
$$

式中: $w_{i, j}$ 是要素 $i$ 和 $j$ 之间的空间权重; $x_{j}$ 是要素 $j$ 的 属性值; $n$ 为要素数量。

\section{3 盲区分析}

可达性盲区主要分为显性和隐性 2 类 $^{[3]}$ 。显性 盲区指所有公园绿地服务范围均未覆盖到的地方, 即可达性指数 $A_{i}$ 为 0 的区域。作为增设公园绿地最 关键的机会空间,显性盲区为绿地系统的完善起到 最显著的指导作用。隐性盲区是指虽然此区域被 公园绿地的服务半径所覆盖, 可达性指数 $A_{i}>0$, 但 由于该区域人口密度较高, 超过了公园绿地的承载 能力, 人均公园绿地面积无法达标, 导致大量居民 不能有效使用绿地。隐性盲区主要存在于绿化水 平较低且人口稠密的高密度居住片区周围, 要同时 结合可达性指数和人口密度进行分析。

\section{3 结果与分析}

\section{1 居住区人口需求}

通常来说, 居住区人口密度和该区域居民对绿 地的需求水平正相关。通过计算各蜂窝网的人口 密度, 得到黄浦区人口密度分布图(图 5)。由图可 知, 黄浦区的居住用地主要分布在中南部, 五里桥 街道、打浦桥街道、半淞园路街道北部以及小东门 街道分布着一些高层住宅, 局部人口密度较大; 老 西门、豫园街道则聚集着大量传统弄堂, 人口密度 为中等水平; 外滩、新天地、人民广场以及黄浦滨江 片区多为商业服务与商务办公用地, 人口密度相对 较低。 


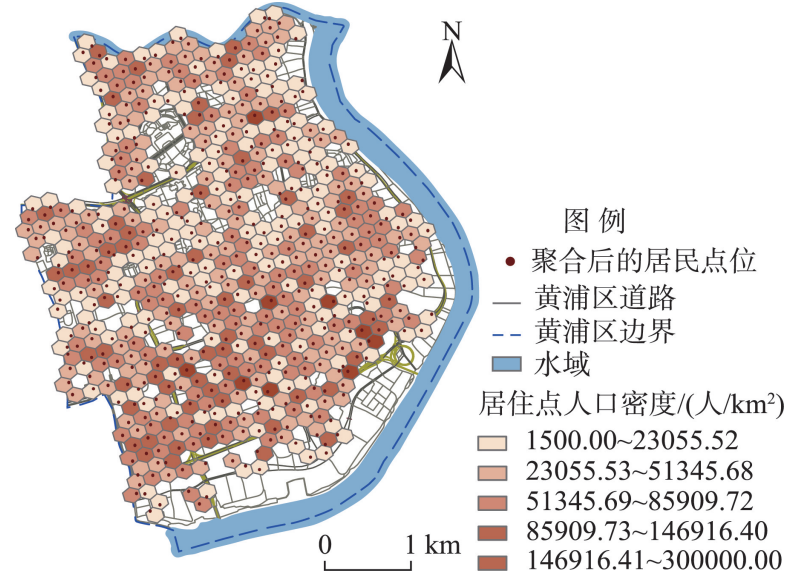

图 5 黄浦区人口密度分布

Fig.5 Population density distribution of Huangpu District, Shanghai

\section{2 公园绿地可达性分级}

通过改进的高斯两步移动模型计算出各居民 点的可达性,基于几何间隔法将计算结果分为可达 性为 0 、可达性低、较低、一般、较高、高, 共 6 个等级 (表2)。如图6 所示, 可达性等级高(28.19 72.23)和 较高(10.91 28.18) 的居住区数量较少, 占总数的 $22.44 \%$, 主要分布于人民广场和新天地附近; 可达 性等级一般(4.13 10.90)的区域分布在北侧的黄浦 江沿线和复兴中路沿线,少量分布在内环高架附 近, 占总数的 $26.21 \%$; 可达性低(0.01 1.45) 和较低 (1.46 4.12)的居住区最多, 占总量的 $42.19 \%$, 主要 分布于黄浦区南部,集中在打浦桥、五里桥和半淞 园路街道,包含的人口数量也最多, 占比 $46.79 \%$ 。 另外, 老西门街道和打浦桥、五里桥的西侧区域存 在服务盲区, 可达性水平为 0 , 包含 $9.16 \%$ 的居住区 和 $10.66 \%$ 的人口。

依据两步移动搜索法的计算原理, 绿地可达性 实际上为加权后的人均绿地面积 ${ }^{[11]}$ 。黄浦区 2020
年计划全区人均绿地面积为 $4.42 \mathrm{~m}^{2} /$ 人, 与一般等 级的下限差不多,约有 $42.56 \%$ 的地区可达性达到全 区平均水平, 还有超过半数的区域不能满足要求。

\section{3 局域自相关分析}

对黄浦区公园绿地空间可达性进行冷热点分 析, 结果如图 7 所示。可见,热点地区主要集中在 北部人民广场和南部南园公园附近,其中北部分布 着如人民公园、延中绿地、广场公园等多个I类大型 公园绿地, 以及众多的II类绿地,构成完善的绿地 层级体系, 且资源竞争小, 可达性水平普遍较高; 南 部组团以I类绿地南园公园为核心, 辅以 3 个 II类绿 地, 局部可达性高值区也同样较多。冷点地区覆盖 黄浦区中南部的大片区域,包含打浦桥、五里桥、老 西门街道等, 这里仅有少量的II类绿地, 绿地资源 严重匮乏; 同时, 有大量居住区分布, 人口密度较 高, 而且路网密度低、道路通达性较差, 可达性普遍 较低。

\section{4 盲区分析}

从公园绿地可达性的分布上看(图 6), 黄浦区 仍存在一些可达性指数为 0 的显性盲区。一部分 位于老西门街道的中部和东部,该区上海传统石库 门民居密布, 几乎没有绿地, 居民的出行及日常游 敀均存在很大的不便; 另一部分位于打浦桥街道的 西南部和五里桥街道的西部,这里同样少有公园绿 地。由于该盲区地处黄浦区的边界, 紧邻徐汇区, 需要考虑边界效应对研究区的影响。经笔者调研 发现,此区域内的居民在本文限定的搜索國内同样 无法抵达徐汇区的公园绿地。但由于此区域内的 居住区大多是配备有小区游园且绿化条件较好的 高层住宅区,居民日常的户外游㕰需求基本可以 满足。

将人口密度大于黄浦区平均水平 3.32 万人 $/ \mathrm{km}^{2}$ 的区域与可达性小于 $4.42 \mathrm{~m}^{2} /$ 人(2020 年黄浦区计

表 2 黄浦区居住区公园绿地可达性水平分级统计

Tab.2 Statistics of accessibility level of park green space in residential areas of Huangpu District, Shanghai

\begin{tabular}{lccccc}
\hline \multirow{2}{*}{ 可达性等级 } & \multicolumn{2}{c}{ 聚合居住区 } & & \multicolumn{3}{c}{ 居住人口 } \\
\cline { 2 - 3 } \cline { 5 - 6 } & 数量 $/$ 个 & 28 & 5.03 & 人口数/人 & 占比 $/ \%$ \\
\hline 高(28.19 72.23) & 97 & 17.41 & 24754 & 3.75 \\
较高(10.91 28.18) & 146 & 26.21 & 95095 & 14.42 \\
一般(4.13 10.90) & 118 & 21.19 & 160827 & 24.39 \\
较低(1.46 4.12) & 117 & 21.00 & 132088 & 20.03 \\
低(0.01 1.45) & 51 & 9.16 & 176459 & 26.75 \\
0 & & & 70289 & 10.66 \\
\hline
\end{tabular}




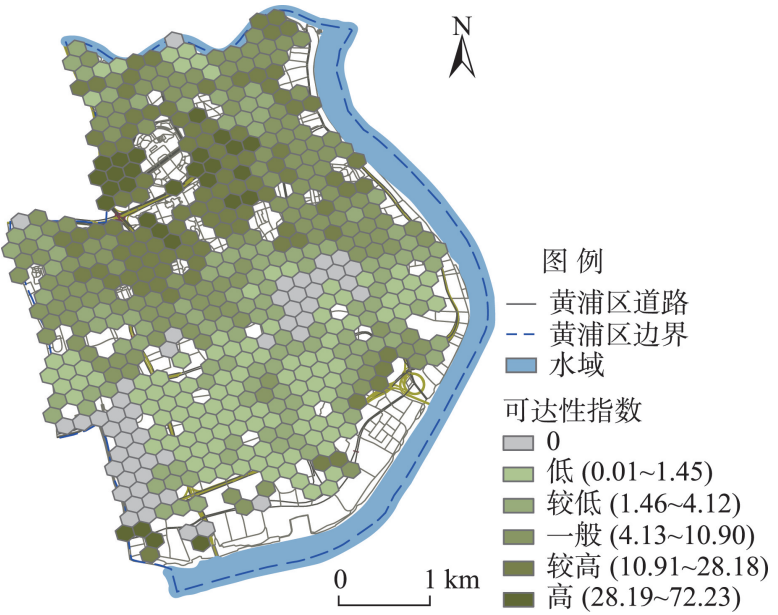

图 6 黄浦区公园绿地可达性空间分级结果

Fig.6 Spatial classification results of accessibility of park green space in Huangpu District, Shanghai

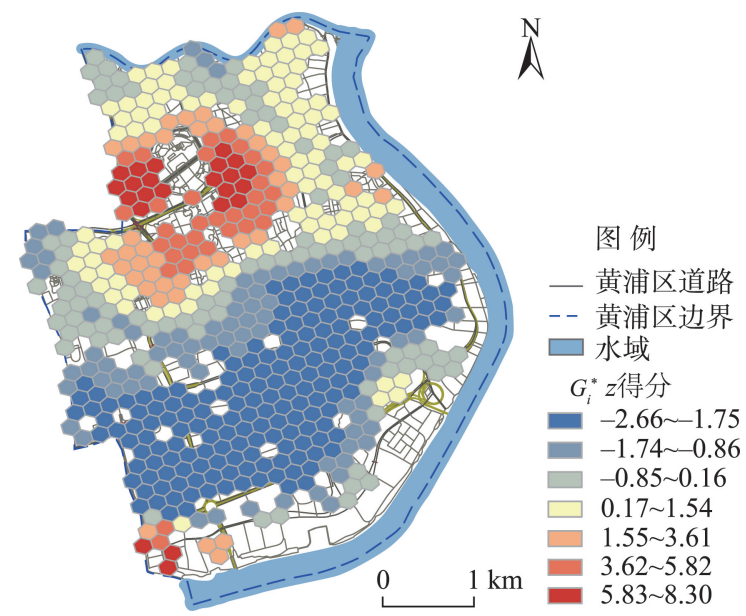

注:图中红色区域表示可达性的高值聚类区,蓝色表示可达 性的低值聚类区, 黄色为无明显聚类关系的区域。

图 7 黄浦区公园绿地可达性冷热点分布

Fig.7 Distribution of cold and hot spots in park green space accessibility in Huangpu District, Shanghai

划全区人均绿地面积)且大于 0 的区域进行叠加。 如图 8 所示, 重叠区域主要集中在黄浦区中南部的 打浦桥、五里桥街道等地, 较高的人口密度和十分 稀少的绿地资源, 使得人均公园绿地无法达标, 形 成隐性盲区。经计算, 隐性盲区占聚合居住区总量 的 $16.5 \%$ 。

研究认为, 显性盲区可通过挖掘存量空间、开 放附属绿地等方式来消除。隐性盲区可以通过提 高路网密度、增设步行天桥, 增设公园出人口、与交 通系统建立良好的耦合关系, 以及沿道路增设小微 公共绿地等方式进行消除。

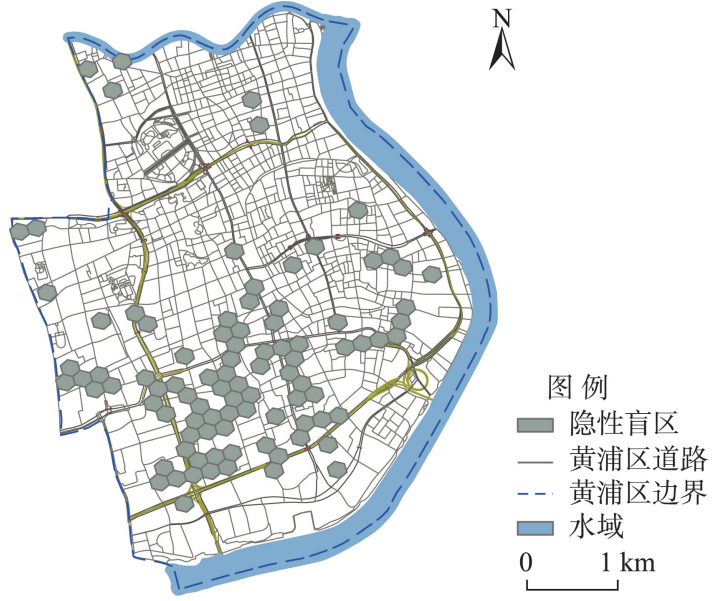

图 8 黄浦区可达性隐性盲区分布

Fig.8 Distribution of invisible blank area in Huangpu District, Shanghai

\section{4 结论与讨论}

\section{1 结论}

本文采用了高斯两步移动搜索模型对黄浦区 现有公园绿地进行步行条件下的空间可达性计算， 并针对其方法上的不足进行以下优化: (1) 与大数据 结合。通过爬取链家网、安居客等房屋交易平台的 居住小区 POI, 获取各居住区的真实人口数据; 并利 用百度地图 API 路径规划接口爬取各供给点和需 求点间基于实时路况的出行时间,克服了传统方法 的数据滞后、出于经验估算、费时费力等弊端; (2) 蜂 窝网化研究区域。将居住小区聚合于边长 $100 \mathrm{~m}$ 的 蜂窝网中, 克服了因居住单元的不规则形状所造成 的统计误差, 同时比正方形网格更加精确 ${ }^{[20]}$; (3) 采 用多阈值搜索法。将公园绿地根据规模差异划分 为不同等级并根据相关政策规定赋予其不同的搜 索阈值。利用ArcGIS 10.6 软件, 对上海市黄浦区 2019 年底 $400 \mathrm{~m}^{2}$ 以上的公园绿地进行可达性的计 算研究。研究结果表明:

(1) 在空间分布上, 黄浦区公园绿地可达性呈 现明显的极化特征。可达性指数的高值区域主要 集中在南北两极,北部是上海市的行政和商业中 心,有人民公园、延中绿地、外滩等大型公园绿地和 广场, 可达性指数普遍处于较高水准; 南部极值主 要集中在南园公园附近, 因人口密度低、资源竞争 力小, 成为可达性的高值区。中南部由于人口密度 大、绿地资源短缺, 成为可达性的低值聚集区。 
(2) 在资源分配上, 可达性指数和人口需求呈 负相关。黄浦区人口密度整体上呈现出由北向南 的递增趋势, 北部人口密度较低, 需求量小, 却分布 着多个品质较高的大型公园绿地; 南部主要为居住 片区, 人口稠密, 需求量大, 但绿地却少, 两者呈现 明显的不匹配现象。由此可见,公园绿地的选址布 局未能将人口需求作为第一影响因素。

(3) 在公园绿地的等级上, 大型公园绿地提升 周围居住区可达性的作用明显。通过公园绿地分 布和可达性指数分析发现, I类大型绿地分布较多 的如南京东路街道、外滩街道、淮海路街道等的可 达性较高。尤其是南园公园附近, 仅此一处大型绿 地就使周围居住区的可达性指数明显提高。而老 西门街道和打浦桥街道, 因缺乏 I 类绿地, 成为 2 个 可达性的低值区。

(4) 在盲区分布上, 黄浦区仍存在部分显性和 隐性盲区。9.16\%的居住区为显性盲区, 可达性为 0 , 即居民在步行 $15 \mathrm{~min}$ 以内无法抵达任何公园绿 地; $16.5 \%$ 的区域为隐性盲区, 虽然可达性大于 0 , 但 因人口密度过高, 公园绿地供不应求。在 “绿地增 量” 建设上不仅要考虑显性盲区的增补, 更要充分 结合人口属性, 加强隐性盲区的公园绿地建设。

\section{2 讨论}

根据本文研究结果, 结合高密度城市更新要求 与黄浦区实际情况, 提出以下几点优化建议:

(1) 适度增量: 进行空间挖潜, 完善绿地空间网 络。重点在盲区内挖掘“零星地块” “消极空间”等 灰色空间, “针尒式” 见缝插绿, 补充完善公园绿地 体系; 适度开放学校、医院等公共设施内的附属绿 地, 采用错时利用方式, 提高绿地的利用效率; 加强 绿道、林荫道的建设与贯通, 提高公园绿地的连通 性, 完善绿地网络体系的同时, 提升利用效率。

(2) 盘活存量: 优化绿地品质, 提高公园绿地的 承载力与服务力。公园绿地的质量对其服务水平 的提升有着重要影响, 在建设密集区无法进行绿地 增量扩展时, 可对存量空间, 尤其是I类公园绿地进 行优化。通过提升公园绿地等级、加强设施建设、 引人精细化管理模式, 提高公园绿地的活动承载力 和服务供给力。

(3) 社区共治: 依据社区共治理念, 实现居民自 下而上、自主更新。以社区为抓手, 倡导居民自发 组织绿化相关活动, 提升居民的绿化参与度、获得 感和幸福感。
本文有待深化的研究内容主要有 3 个方面:一 是在盲区分析中, 有待就其公园绿地短缺程度的差 异做进一步分析; 二是基于公园绿地的分类分级和 数量, 深化公园绿地质量、社区主要人群的需求差 异研究; 三是在出行方式上, 本文基于研究区域相 关政策目标, 选取了影响社区居民公园游礉效能中 最主要的步行方式, 考虑到实际生活中, 特别是中 青年居民, 还可以选择自行车、公交车等方式前往 公园绿地, 不同出行方式在 $15 \mathrm{~min}$ 内的可达性范围 也不同,尚待之后研究的进一步探讨。

\section{参考文献(References)}

[1] 俞孔坚, 段铁武, 李迪华, 等. 景观可达性作为衡量城市 绿地系统功能指标的评价方法与案例 [J]. 城市规划, 1999, 23(8): 8-11, 43. [Yu Kongjian, Duan Tiewu, Li Dihua, et al. Landscape accessibility as a measurement of the function of urban green system. City Planning Review, 1999, 23(8): 8-11, 43. ]

[2] Hansen W G. How accessibility shapes land use [J]. Journal of the American Institute of Planners, 1959, 25(2): 7376.

[3] Tamosiunas A, Grazuleviciene R, Luksiene D, et al. Accessibility and use of urban green spaces, and cardiovascular health: Findings from a Kaunas cohort study [J]. Environmental Health, 2014, 13(1): 20. doi: 10.1186/1476-069X13-20.

[4] Perry B, Gesler W. Physical access to primary health care in Andean Bolivia [J]. Social Science \& Medicine, 2000, 50(9): 1177-1188.

[5] Talen E. Measuring the public realm: A preliminary assessment of the link between public space and sense of community [J]. Journal of Architectural and Planning Research, 2000, 17(4): 344-360.

[6] Nicholls S. Measuring the accessibility and equity of public parks: A case study using GIS [J]. Managing Leisure, 2001, 6(4): 201-219.

[7] 尹海伟, 孔繁花, 宗跃光. 城市绿地可达性与公平性评价 [J]. 生态学报, 2008, 28(7): 3375-3383. [Yin Haiwei, Kong Fanhua, Zong Yueguang. Accessibility and equity assessment on urban green space. Acta Ecologica Sinica, 2008, 28(7): 3375-3383. ]

[8] Hillsdon M, Panter J, Foster C, et al. The relationship between access and quality of urban green space with population physical activity [J]. Public Health, 2006, 120(12): 1127-1132.

[9] 宋正娜, 陈雯, 车前进, 等. 基于改进潜能模型的就医空 
间可达性度量和缺医地区判断: 以江苏省如东县为例 [J]. 地理科学, 2010, 30(2): 213-219. [Song Zhengna, Chen Wen, Che Qianjin, et al. Measurement of spatial accessibility to health care facilities and defining health professional shortage areas based on improved potential model: A case study of Rudong County in Jiangsu Province. Scientia Geographica Sinica, 2010, 30(2): 213-219. ]

[10] Radke J, Mu L. Spatial decompositions, modeling and mapping service regions to predict access to social programs [J]. Geographic Information Sciences, 2000, 6(2): 105-112.

[11] 魏冶, 修春亮, 高瑞, 等. 基于高斯两步移动搜索法的沈 阳市绿地可达性评价 [J]. 地理科学进展, 2014, 33(4): 479-487. [Wei Ye, Xiu Chunliang, Gao Rui, et al. Evaluation of green space accessibility of Shenyang using Gaussian based 2-step floating catchment area method. Progress in Geography, 2014, 33(4): 479-487. ]

[12] 陶卓霖, 程杨, 戴特奇. 北京市养老设施空间可达性评 价 [J]. 地理科学进展, 2014, 33(5): 616-624. [Tao Zhuolin, Cheng Yang, Dai Teqi. Measuring spatial accessibility to residential care facilities in Beijing. Progress in Geography, 2014, 33(5): 616-624. ]

[13] 李孟桐, 杨令宾, 魏冶. 高斯两步移动搜索法的模型研 究: 以上海市绿地可达性为例 [J]. 地理科学进展, 2016, 35(8): 990-996. [Li Mengtong, Yang Lingbin, Wei Ye. Improved Gaussian based 2-step floating catchment area method: A case study of green space accessibility in Shanghai. Progress in Geography, 2016, 35(8): 990-996. ]

[14] 徐彦秒, 曹娓, 何瑞珍. 结合建筑人口容量的南阳市公 园可达性分析 [J]. 浙江农业科学, 2015, 56(4): 492496. [Xu Yanmiao, Cao Wei, He Ruizhen. Accessibility analysis of parks in Nanyang based on building population capacity. Zhejiang Agricultural Sciences, 2015, 56 (4): 492-496. ]

[15] 马林兵, 曹小曙. 基于 GIS 的城市公共绿地景观可达性 评价方法 [J]. 中山大学学报(自然科学版), 2006, 45(6): 111-115. [Ma Linbing, Cao Xiaoshu. A GIS-based evaluation method for accessibility of urban public green landscape. Acta Scientiarum Naturalium Universitatis Sunyatseni, 2006, 45(6): 111-115. ]

[16] 赵晓龙, 郑权一, 刘笑冰, 等. 基于 2SFCA 改进模型的城 市公园绿地规划配置研究: 以深圳福田区为例 [J]. 中 国园林, 2018, 34(S2): 95-99. [Zhao Xiaolong, Zheng Quanyi, Liu Xiaobing, et al. Study on the planning and allocation of urban park green space based on 2SFCA improved model: A case study of Futian District, Shenzhen. Chinese Landscape Architecture, 2018, 34(S2): 95-99. ]

[17] 卢宁, 李俊英, 间红伟, 等. 城市公园绿地可达性分析:
以沈阳市铁西区为例 [J]. 应用生态学报, 2014, 25(10): 2951-2958. [Lu Ning, Li Junying, Yan Hongwei, et al. Analysis on accessibility of urban park green space: The case study of Shenyang Tiexi District. Chinese Journal of Applied Ecology, 2014, 25(10): 2951-2958. ]

[18]《黄浦年鉴》编纂委员会. 黄浦年鉴 2018 [M]. 上海: 上 海文化出版社, 2018. [Huangpu District Yearbook Compilation Committee. Huangpu District Yearbook 2018. Shanghai, China: Shanghai Culture Press, 2018. ]

[19] 单卓然, 张衔春, 黄亚平. 武汉都市发展区及主城区城 镇常住人口空间分布格局: 基于 2010 年第六次人口普 查数据 [J]. 人文地理, 2016, 31(2): 61-67. [Shan Zhuoran, Zhang Xianchun, Huang Yaping. The research on the spatial distribution layout of city permanent residents in metropolitan development area and main urban area in Wuhan: Based on the Sixth Census in 2010. Human Geography, 2016, 31(2): 61-67. ]

[20] Rogers C A. Packing and covering [M]. Cambridge, UK: Cambridge University Press, 1964.

[21] 王奇. 基于改进两步移动搜索法的上海市医疗服务可 达性分析 [D]. 武汉: 武汉大学, 2019. [Wang Qi. Accessibility analysis of medical services in Shanghai based on improved 2SFCA. Wuhan, China: Wuhan University, 2019. ]

[22] Luo W, Qi Y. An enhanced two-step floating catchment area (E2SFCA) method for measuring spatial accessibility to primary care physicians [J]. Health \& Place, 2009, 15(4): 1100-1107.

[23] Dai D J, Wang F H. Geographic disparities in accessibility to food stores in southwest Mississippi [J]. Environment and Planning B: Planning and Design, 2011, 38(4): 659-677.

[24] Dai D J. Racial/ethnic and socioeconomic disparities in urban green space accessibility: Where to intervene ? [J]. Landscape and Urban Planning, 2011, 102(4): 234-244.

[25] Jamtsho S, Corner R, Dewan A. Spatio-temporal analysis of spatial accessibility to primary health care in Bhutan [J]. ISPRS International Journal of Geo- Information, 2015, 4(3): 1584-1604.

[26] Luo W, Whippo T. Variable catchment sizes for the twostep floating catchment area (2SFCA) method [J]. Health \& Place, 2012, 18(4): 789-795.

[27] McGrail M R, Humphreys J S. A new index of access to primary care services in rural areas $[\mathrm{J}]$. Australian and New Zealand Journal of Public Health, 2009, 33(5): 418423.

[28] 陶卓霖, 程杨. 两步移动搜寻法及其扩展形式研究进展 [J]. 地理科学进展, 2016, 35(5): 589-599. [Tao Zhuolin, 
Cheng Yang. Research progress of the two- step floating catchment area method and extensions. Progress in Geography, 2016, 35(5): 589-599. ]

[29] Wang F H. Measurement, optimization, and impact of health care accessibility: A methodological review [J]. Annals of the Association of American Geographers, 2012, 102(5): 1104-1112.

[30] Anselin L. Local indicators of spatial association-LISA
[J]. Geographical Analysis, 1995, 27(2): 93-115.

[31] 赵兵, 李露露, 曹林. 基于 GIS 的城市公园绿地服务范 围分析及布局优化研究: 以花桥国际商务城为例 [J]. 中国园林, 2015, 31(6): 95-99. [Zhao Bing, Li Lulu, Cao Lin. GIS-based analysis of city park green space service range and layout optimization: A case study in Huaqiao International Business City. Chinese Landscape Architecture, 2015, 31(6): 95-99. ]

\title{
Spatial accessibility of park green space in Huangpu District of Shanghai based on modified two-step floating catchment area method
}

\author{
REN Jiayi, WANG Yun* \\ (School of Design, Shanghai Jiao Tong University, Shanghai 200240, China)
}

\begin{abstract}
In order to solve the problem of unbalanced supply and demand of park green space in high density cities, this study used a Gaussian based two- step floating catchment area method to analyze the spatial accessibility of existing park green space in Huangpu District of Shanghai, under walking conditions. First, we extracted the point of interest (POI) data of residential areas from the Internet and aggregated them into a $100 \mathrm{~m}$ long hexagonal cellular network to calculate the number of people and population density, then through the Application Programming Interface (API) of Baidu Map we extracted the travel time between supply and demand points based on actual road conditions. Second, the paper took the park green space built by the end of 2018 in Huangpu District of Shanghai as an example, and considered the four aspects of residents' demand, accessibility classification, cold and hot spots, and blank areas. The results show that the accessibility level of park green space in Huangpu District is higher in the north and lower in the south, which is negatively correlated with the population density distribution. The dominant blind areas $(9.16 \%$ of the total area) and the recessive blind areas (16.5\% of the total area) should be eliminated. This study made a quantitative analysis on the supply and demand allocation, to provide guidance for the further optimization of green space layout and site selection. Finally, recommendations were made from three aspects of "increasing green space appropriately", "strengthening the quality of existing green space" and "community co-governance", in order to provide theoretical support for the Fourteenth Five-Year Plan of greening Huangpu District.
\end{abstract}

Keywords: park accessibility; Gaussian based two-step floating catchment area (2SFCA) method; fine-grained population data; big data; Huangpu District of Shanghai 